\title{
Peritoneal implantation of ureter in cadaveric renal transplant
}

\author{
CF Tsang, WK Ma *, FK Cheung
}

\begin{abstract}
A B S T R A C T
We report here a case of complication of peritoneal implantation of ureter in cadaveric renal transplant. The patient presented with anuria and delayed graft function. The diagnosis was suspected upon physical examination and radiological investigation. The complication was managed with reimplantation of the ureter into the bladder and the patient recovered with good graft function. We discuss this case, review the literature on this rare complication, and share our suggestions on how it can be prevented.
\end{abstract}

\author{
Hong Kong Med J 2015;21:269-71 \\ DOI: $10.12809 / \mathrm{hkmj} 134171$ \\ ${ }^{1}$ CF Tsang, MB, BS, MHKIBSC \\ ${ }^{2}$ WK Ma *, FRCS, FHKAM (Surgery) \\ ${ }^{1}$ FK Cheung, FRCS, FHKAM (Surgery) \\ 1 Urology Division, Department of Surgery, Princess Margaret Hospital, \\ Laichikok, Hong Kong \\ 2 Urology Division, Department of Surgery, The University of Hong Kong, \\ Queen Mary Hospital, Hong Kong \\ * Corresponding author: kitkitma@yahoo.com
}

\section{Introduction}

Oliguria or anuria early after cadaveric renal transplant (CRT) is not uncommon and can be related to numerous causes. We report here a rare case of complication of ureteric implantation in the peritoneum in CRT causing anuria. Diagnosis was suspected early on day 1 after operation by clinical examination and abdominal X-ray (AXR), and confirmed with non-contrast computed tomography (CT) of the abdomen and pelvis. The complication was managed with immediate reimplantation of the ureter into the bladder and the patient had an uneventful recovery thereafter with good graft function. To our knowledge, this is the first reported case in Hong Kong and the fifth in the world. We believe the actual incidence is underreported and would like to share our suggestions on how to avoid this rare complication.

\section{Case report}

A 29-year-old man with Alport's syndrome developed end-stage renal failure in 2009 and was started on intermittent peritoneal dialysis in 2011. His serum creatinine level and estimated glomerular filtration rate were $1458 \mu \mathrm{mol} / \mathrm{L}$ and $5.1 \mathrm{~mL} / \mathrm{min}$, respectively. In September 2013, he received CRT from a 60-yearold man with brain stem death due to haemorrhagic stroke. The donor's serum creatinine was $88 \mu \mathrm{mol} / \mathrm{L}$ and there were no hypotensive episodes or inotrope infusion before organ harvesting.

The cadaveric right kidney was transplanted into the right iliac fossa of the recipient, with good perfusion and turgor after release of vascular clamps. No urine was noted at cut-end of the graft ureter at the time of implantation. A needle test to aspirate pre-filled gentamicin solution from the bladder was done and extravesical ureteroneocystostomy with Lich-Gregoir technique was performed with a 7French, 15-cm long, double J ureteric stent in situ. The total operating time was 2 hours and 20 minutes; with cold ischaemic time of 7 hours 41 minutes and second warm ischaemic time of 33 minutes. The patient was haemodynamically stable but remained anuric 12 hours after operation with a serum creatinine level of $1268 \mu \mathrm{mol} / \mathrm{L}$. An urgent Doppler ultrasound of the graft kidney was done and showed good perfusion of graft with patent renal artery and vein. Repeated physical examination revealed a slightly distended abdomen and AXR showed the distal coil of double J stent above the pelvis level (Fig a), leading to the suspicion of implantation of the ureter into the peritoneum. Subsequent noncontrast $\mathrm{CT}$ of the abdomen and pelvis confirmed placement of the ureteric stent outside the bladder (Fig b and c).

Exploration and reimplantation of ureter were performed immediately. It was noted that the ureter was implanted into the thickened peritoneum at a level just above the right upper lateral bladder wall, with urine draining into the intra-abdominal cavity. The detrusor layer was thin and not well developed. The anastomosis was taken down and ureteroneocystostomy was refashioned with the same Lich-Gregoir technique. There was immediate return of good urine output and his serum creatinine levels improved to $186 \mu \mathrm{mol} / \mathrm{L}$ and $126 \mu \mathrm{mol} / \mathrm{L}$ on postoperative day 3 and week 4, respectively.

\section{Discussion}

Post-renal transplant urological complications are not uncommon. Commonly reported complications 


\section{屍腎移植中輸尿管的植進腹膜 \\ 曾昭鋒、馬偉傑、張富強}

本文報告一宗屍腎移植中輸尿管植進腹膜的併發症。病人術後出現缺 尿及腎功能未見改善, 經臨床及影像檢查後懷疑輸尿管植進腹膜。經 手術把輸尿管重新植入膀胱後, 病人康復而且腎功能良好。除報告此 病例, 本文還回顧有關文獻及分析如何避免此併發症的發生。 include thromboembolic events of vascular anastomosis, acute tubular necrosis, lymph leak, and urinary reflux. Recent retrospective series have reported incidence rates of $2.8 \%$ to $15.5 \%$ of urological complications after CRT. ${ }^{1-3}$ These are significantly decreased rates compared with those in an earlier series after introduction of various modified techniques of implantation and use of ureteric stents. ${ }^{1}$ Peritoneal implantation of ureter constitutes an incidence of $0.1 \%$ to $0.2 \%$ only. Gibbons et $\mathrm{al}^{4}$ reported a case of ureteric implantation into an ovarian cyst in addition to two cases into the peritoneum in a series of 1000 CRT recipients. We believe the actual incidence is underreported, given the general impression that this complication is solely technically related. The Table ${ }^{3-6}$ summarises all reported cases of peritoneal implantation of graft ureter in the current literature.

All reported patients presented with postoperative anuria, with one patient developing ascites, abdominal pain, anuria, and sudden shock. ${ }^{5}$ Timing of diagnosis had been reported from immediate postoperation to few weeks later. A high level of suspicion remains the key for reaching the diagnosis. Common contributing factors identified from the literature and our case include long-term peritoneal dialysis with thickened peritoneum, and the presence of residual peritoneal fluid mimicking urine in the bladder. Therefore, this complication should be suspected in such a patient with unexplained delayed graft function. Tan et $\mathrm{al}^{6}$ suggested that an unexplained rise in ultrafiltration volume in transplanted peritoneal dialysis patients accompanied by a fall in baseline serum creatinine is highly suggestive of the diagnosis. If ureteric stenting was employed, imaging such as AXR and CT scan can help identify the position of the ureteric stent and confirm the diagnosis. Definitive diagnosis can only be established upon exploration.

A note of caution on ways to prevent this rare surgical complication would be more beneficial than treating it. We suggest several measures to avoid it, which have not been discussed in previous reports. Regarding the technique of ureteric implantation, the classic transvesical Leadbetter-Politano technique
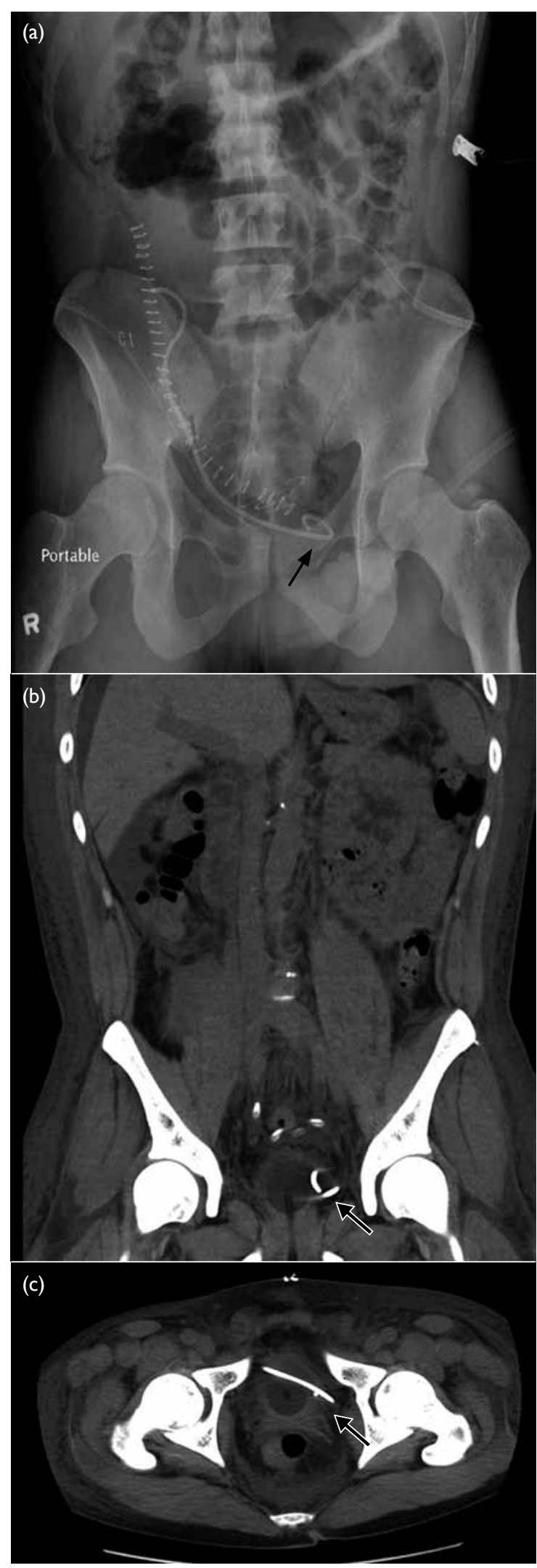

FIG. Kidney ureter bladder: (a) X-ray showing distal coil of ureteric stent above the pelvis level (arrow); (b) computed tomography (CT) with coronal reconstruction showing position of the ureteric stent (arrow), and (c) CT scan showing tip of the ureteric stent outside the bladder (arrow) 
TABLE. Summary of reported cases of peritoneal implantation of graft ureter ${ }^{3-6}$

\begin{tabular}{|c|c|c|c|c|c|}
\hline Study & $\begin{array}{l}\text { No. of } \\
\text { cases }\end{array}$ & Presentation & Time of diagnosis & Diagnosis & Contributing factors identified \\
\hline Gibbons et al, ${ }^{4} 1992$ & 2 & N/M & $\mathrm{N} / \mathrm{M}$ & N/M & CAPD patients with thickened peritoneum \\
\hline $\begin{array}{l}\text { Blanco Parra et al, }{ }^{5 *} \\
2002\end{array}$ & 1 & $\begin{array}{l}\text { Anuria, abdominal } \\
\text { pain, ascites, shock }\end{array}$ & $\begin{array}{l}\text { Day } 0 \text { (immediate } \\
\text { postoperation) }\end{array}$ & Exploration & $\begin{array}{l}\text { Poor exposure, thickened peritoneum } \\
\text { secondary to recurrent peritonitis, presence } \\
\text { of residual peritoneal dialysis fluid }\end{array}$ \\
\hline Tan et al, ${ }^{6} 2003$ & 1 & $\begin{array}{l}\text { Anuria, high } \\
\text { ultrafiltration volume }\end{array}$ & Week 4 & AXR & CAPD patient with thickened peritoneum \\
\hline Davari et al, ${ }^{3} 2006$ & 1 & N/M & $\mathrm{N} / \mathrm{M}$ & N/M & $\mathrm{N} / \mathrm{M}$ \\
\hline Present study & 1 & $\begin{array}{c}\text { Anuria, abdominal } \\
\text { distension }\end{array}$ & Day 1 after operation & AXR, CT scan & $\begin{array}{l}\text { IPD patient with thickened peritoneum, } \\
\text { presence of residual peritoneal dialysis fluid, } \\
\text { thin-walled bladder }\end{array}$ \\
\hline
\end{tabular}

Abbreviations: $A X R=$ abdominal $X$-ray; $C A P D=$ continuous ambulatory peritoneal dialysis; $C T=$ computed tomography; IPD = intermittent peritoneal dialysis; $\mathrm{N} / \mathrm{M}=$ not mentioned

* Article in Spanish, with an English abstract

in which two cystostomies are required, is now replaced by the extravesical Lich-Gregoir technique which requires only one cystostomy and, hence, less bladder dissection, shorter ureteral length, and no interference with native ureteral function. ${ }^{7}$ This technique, however, may pose challenges in recipients previously on peritoneal dialysis, as the peritoneum is thickened due to exposure to dialysis fluid and episodes of peritonitis, if any. A thickened peritoneum, with the presence of residual peritoneal fluid upon incision, can easily be mistaken as the bladder during transplantation. In our practice, the bladder is filled with 80 to $100 \mathrm{~mL}$ of gentamicin solution before the procedure and needle aspiration test is done before ureteric implantation to aid identification of the bladder. Our case illustrated that even with these standard precautions, one may not be able to completely prevent this complication. Tagging up the extravesical tissue with parallel stay sutures on both sides of the 2 to $3 \mathrm{~cm}$ submucosal tunnel before creating the cystostomy will help identify the bladder and peritoneum vigilantly, avoiding shifting of the incision site to the peritoneum instead of the bladder wall after the needle test. If the bladder is scarred and non-compliant due to neuropathic bladder or prolonged anuria, identification of the junction between the peritoneum and bladder wall may become difficult. Preoperative emptying of all peritoneal dialysis fluid is advocated so that if there is nil drainage of bladder content after making the incision, entry into the abdominal cavity instead of the bladder can be suspected. Direct visualisation of the urethral catheter should be the best way to ensure the correct cavity is entered. A larger cystostomy, however, is often required and is not preferred.

Another innovative trick to pick up the complication, should the implantation be done already, is to notice the colour of effluent from the bladder after ureteroneocystostomy. Any urine or antibiotic solution drained in the early postoperative period is at least lightly blood-stained because of the disturbance to the mucosal edges during cystostomy. The absence of blood-stained effluent after ureteric implantation should raise the suspicion that the peritoneum, and not bladder, was opened.

Our report suggests that peritoneal implantation of ureter in CRT is not only technically related but also involves multiple contributing factors. A high index of suspicion is required to pick up this complication and meticulous measures should be adopted to avoid its occurrence.

\section{References}

1. Zavos G, Pappas P, Karatzas T, et al. Urological complications: analysis and management of 1525 consecutive renal transplantations. Transplant Proc 2008;40:1386-90.

2. Praz V, Leisinger HJ, Pascual M, Jichlinski P. Urological complications in renal transplantation from cadaveric donor grafts: a retrospective analysis of 20 years. Urol Int 2005;75:144-9.

3. Davari HR, Yarmohammadi H, Malekhosseini SA, Salahi H, Bahador A, Salehipour M. Urological complications in 980 consecutive patients with renal transplantation. Int J Urol 2006;13:1271-5.

4. Gibbons WS, Barry JM, Hefty TR. Complications following unstented parallel incision extravesical ureteroneocystostomy in 1,000 kidney transplants. J Urol 1992;148:38-40.

5. Blanco Parra M, Calviño J, Romero Burgos R, et al. Ureteral implantation in peritoneum. Exceptional complication in renal transplantation [in Spanish]. Actas Urol Esp 2002;26:579-80.

6. Tan SY, Lim CS, Teo SM, Lee SH, Razack A, Loh CS. Peritoneal implantation of ureter in a cadaveric kidney transplant recipient. Med J Malaysia 2003;58:769-70.

7. Zhao JJ, Gao ZL, Wang K. The transplantation operation and its surgical complications. In: Ortiz J, Andre J, editors. Understanding the complexities of kidney transplantation. China: InTech; 2011: 466-7. 